\title{
Research in Effect of Feeding Speed on Turning Vibration of Slender Shaft with Moving Load Theory
}

\author{
Hai Lin ${ }^{1, a}$, Xin-Yong Mao ${ }^{2, b}$ and Wen-Jie Wan ${ }^{3, c}$ \\ ${ }^{1}$ Huazhong University of Science and Technology School of Mechanical Science and \\ Engineering,wuhan, CHINA country \\ ${ }^{2}$ Huazhong University of Science and Technology School of Mechanical Science and \\ Engineering,wuhan, CHINA \\ ${ }^{3}$ Huazhong University of Science and Technology School of Mechanical Science and \\ Engineering, wuhan, CHINA \\ a1076993501@qq.com, b maoxyhust@hust.edu.cn, c15827467892@163.com
}

\begin{abstract}
Keywords: slender shaft, turning vibration, moving load, feed rate change, influencing factors Abstract. In the turning process, the slender shaft workpiece is one of the difficult parts. Especially the action of load on the surface of rotary workpiece and interaction between the workpiece vibration and cutting force increase the vibration of the workpiece and even cause flutter. Based on the theory of moving load, this paper has designed the concrete experiment, analyzed the cutting force in three directions, the surface vibration and roughness of the workpiece, the modal parameters of the workpiece and the tool, the self-power spectral density of the tool and so on. The change rule of six influencing factors with the change of feed rate also validates the correctness of the moving load theory. Through the analysis of the surface vibration and roughness of the workpiece, the degree of vibration of the workpiece increases and even the flutter phenomenon increases with the increase of the feed speed in a certain range. When the feed rate increases to a certain value, the degree of vibration of the workpiece has a tendency to weaken. The conclusion has certain guiding significance and application value to reduce the vibration and even flutter phenomenon, and provides a theoretical basis for applying the moving load theory to the complicated structure research on cutting vibration of shaft parts.
\end{abstract}

\section{Introduction}

Machine tool vibration is a dynamic instability of the machining system, which is one of the main faults in the machining process. Production of machine cutting vibration is an important reason for the quality of the workpiece processing, and it affects the use of machine tools and life of cutters, which can not even make the machining process. At present, the research on cutting vibration is to analyze the formation mechanism of vibration or flutter, establish the stability model of cutting vibration, carry out stability prediction and flutter analysis, and explore the method of controlling or suppressing the vibration of slender workpiece [1] and reducing the processing error, etc., but research on cutting force moving speed for the impact of cutting vibration is very little. In the 1940s, Taylor [2] first proposed the phenomenon of cutting chatter. Tobias and Fishwick [3-5] proposed regeneration flutter formation mechanism and established a rectangular cutting regeneration flutter model, who pointed out that the regeneration flutter is mainly caused by the change of machining thickness. In the calculation of cutting vibration modeling, Tobias [5] studied the influence of cutting width and workpiece speed on cutting stability by using the bode diagram. Tlusty and Merrit et al. [6,7] used the control engineering theory to solve the critical cutting width. Vela-Martinez et al. [8,9] considered the effect of workpiece and tool vibration on processing and got processing stability analysis Lobe diagram. Due to the great length-diameter ratio (such as greater than 10) of the shaft parts [1], the workpiece is prone to bending deformation and vibration or even flutter phenomenon. Many scholars at home and abroad study the vibration of elongated shaft workpiece in the cutting process.Domestic scholar zhao haitao et al. $[10,11]$ analyzes the dynamic analysis of turning slender axle by using finite 
element method. Cui Bodi [12] establishes a machining error prediction model, which points out that the clamping method of elongated workpiece, the turning parameters and the stiffness of the knife and other factors affect the machining error of the workpiece.

At the same time, the domestic and foreign scholars have also carried out an in-depth study on the theory of moving load. Ouyang [1] analyzes the vehicle-bridge model, and obtains the relationship between the critical velocity of the bridge and the natural frequency of the bridge, indicating that the load velocity affects the bridge vibration. Ouyang studies the dynamics of structural vibration under various loads, and proposes a three-dimensional moving load model with Wang $[13,14]$. The dynamic analysis of the fixed rotating structure of the axial - blade, axial - disk and so on was carried out by ZHANG Wen-lu [15] and ZHOU Xun [16]. Katz et al. [17-19] establish a one-dimensional and two-dimensional load dynamics model at constant speed, analyze the vibration response and stability of the rotating shaft, and point out the speed and load axial velocity impact system response. Based on the theory of moving load, the effect of feed rate change on the workpiece and tool in the turning vibration of slender shaft is studied. The change rules of the six influenced factors are analyzed deeply including cutting force in three directions, the modal parameters ,the surface vibration and roughness of the workpiece, the modal parameters, the self-power spectral density of the tool with the changes in the rate of feed, which verify the correc tness of the applying of moving load theory for slender shaft turning process.

\section{Study on Vibration Model of Moving Load Theory}

In mechanical machining, the moving load acting on the surface of the rotating elongated workpiece causes the workpiece to a greater vibration and even a flutter, and this interaction between the workpiece and the moving load is called the moving load theory. As shown in the figure 1, a simple moving load model is established. The vehicle with mass $\mathrm{m}$ travels at a constant speed over a long bridge [10]. When the vehicle moving speed $u$ and the natural frequency $w$ of the beam satisfy the following equation 1, resonance occurs. By deriving the formula from the model, the natural frequency of the beam satisfies the following formula [1]:

$$
\begin{aligned}
& w_{n}=\frac{n \pi u}{l}(n=1,2,3,4, \ldots) \\
& \frac{n \pm j}{l} \pi u=w_{j}+w_{n}(j, n=1,2,3,4, \ldots ; n \geq j) \\
& \frac{n \pm j}{l} \pi u=w_{n}-w_{j}(j, n=1,2,3,4, \ldots ; n \geq j)
\end{aligned}
$$

In Equation 2, each contains at least one resonant frequency or modal, so the frequencies of these equations are called the combined resonant frequencies. When the natural frequency of the beam and the moving speed of the mass satisfy any of the above two conditions, that is, when the moving speed of the load satisfies a certain relationship with the natural frequency of the carrier, it will cause the carrier to resonate. On the Lobe diagram shown in the figure 2, the main analysis of the spindle speed and cutting depth (or cut width) is the impact of processing stability, but the feed rate which affects the carrier vibration is not too much to consider. Based on the analysis of the moving load model, it can be found that the moving speed of the moving load affects the vibration of the carrier. The turning feed rate is the moving speed of the moving load, and the moving load theory can be applied to the analysis of turning vibration to study the effect of feed rate.

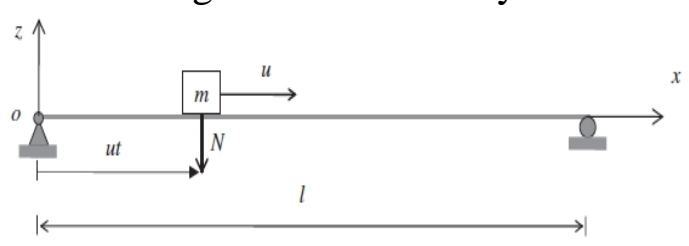

Figure 1 Vehicle - bridge model under moving load

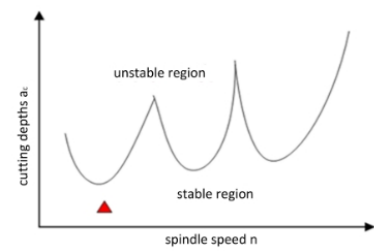

Figure 2 Lobes of stability analysis 


\section{Effect of Feeding Speed on Slender Workpieces Vibration}

The effects of the change of feed rate on turning vibration are analyzed with slender workpiece (ie bar) as the research object. After designing the specific turning experiment and collecting the vibration signal of the workpiece, the effect of the feed speed change on the vibration of the workpiece and the workpiece surface quality is explored. The feed rate affects the vibration of the workpiece, which affects the modal parameters of the workpiece, the vibration displacement, the surface vibration and the surface roughness. Some feed rates such as $95 \mathrm{~mm} / \mathrm{min}$ have a great influence on these factors. The theory of mobile loading is verified and feed rate can also make the Lobe diagram stable state instability.

\section{Experiment Layout of Turning Vibration}

The overall layout of the experiment is shown in Figure 3, Figure 4 (a) and (b). The dynamometer and the eddy current sensor are used to measure the cutting force and vibration displacement of the workpiece respectively. A special eddy current sensor fixture is designed for experiment on the Chinese and foreign CNC system CK60 horizontal CNC, which is sliding along the guide rail with the slide, and the eddy current sensor on the fixture can synchronize the lateral feed motion with the tool in the turning process. The design of the special fixture is shown in Figure 5. the cutting parameters in the stable cutting area are selected in figure 6.

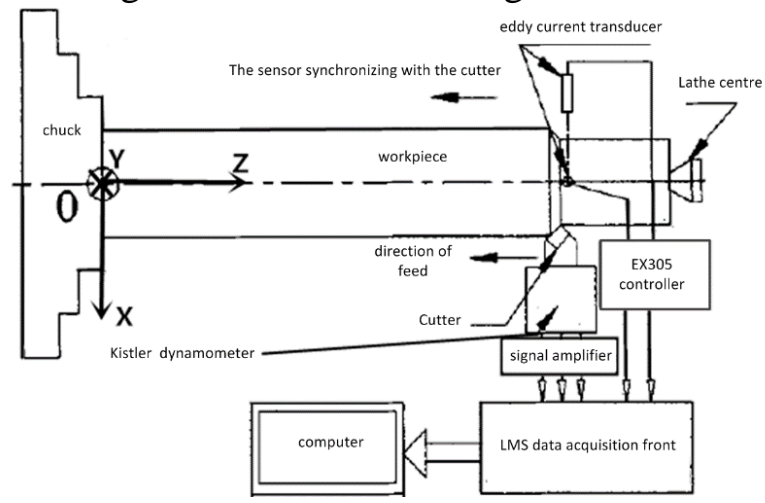

Fig 3 Change into feed speed turning experiment layout

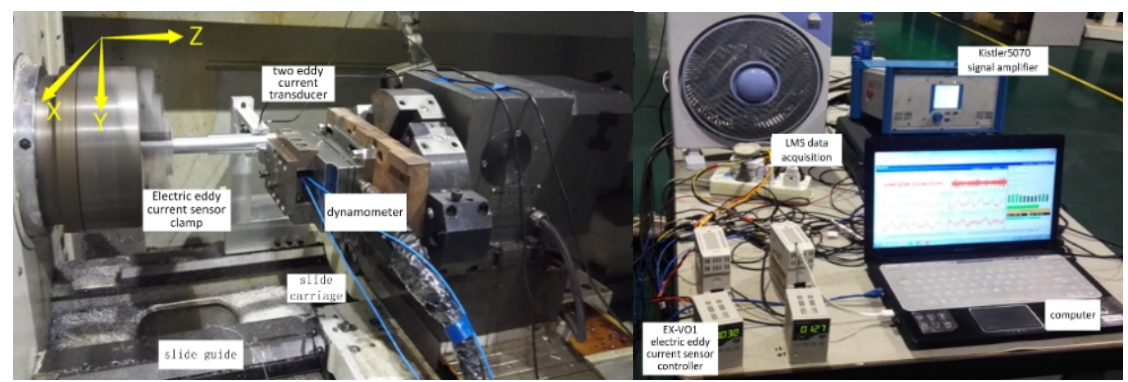

(a) Workpiece and sensor layout

(b) Data collection system

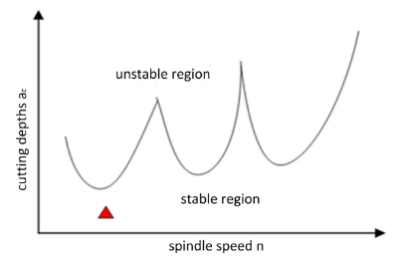

Fig 6 Stability lobe diagram

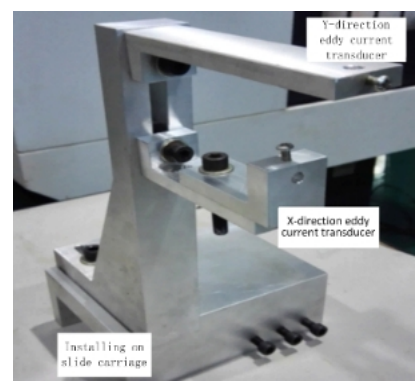

Fig 5 eddy current sensor fixture

Fig 4 Experimental device for change into feed speed turning

\section{Static and Dynamic Mode Analysis of Workpiece}

The aluminum alloy bar workpiece with length of $\mathrm{L}=550 \mathrm{~mm}$ is clamped on the Central China CNC system CK60 horizontal CNC lathe, and four three-way acceleration sensors are evenly arranged at the $350 \mathrm{~mm}$ segment in the middle of the workpiece. The percussion test is conducted at four points with the PCB force hammer in the Y direction.. The natural frequency of the workpiece is given below table 1 . When turning slender workpiece at different feed speed, the workpiece dynamic mode analysis experiment is carried out. The vibration frequency of the workpiece is given below table 2. Compared with Table 1 and Table 2, it can be found that when the feed rate is $95 \mathrm{~mm} / \mathrm{min}$, the multi-stage vibration frequencies of the workpiece can be stirred. The speed has little influence on the low order frequencies but has great influence on the high order frequencies. 
Table 1 Each order natural frequencies of the workpiece static stroke

\begin{tabular}{cccc}
\hline modal order & dian2 natural frequency $(\mathrm{Hz})$ & $\operatorname{dian} 3$ natural frequency $(\mathrm{Hz})$ & dian4 natural frequency $(\mathrm{Hz})$ \\
\hline 1 & 259.085 & 258.368 & 258.058 \\
2 & 374.977 & 375.911 & 384.105 \\
3 & 417.273 & 417.129 & 407.407 \\
4 & 915.648 & 916.483 & 918.341 \\
\hline
\end{tabular}

Table 2 Vibration frequency of workpiece under different feed speed

\begin{tabular}{|c|c|c|c|c|c|}
\hline $\begin{array}{c}\text { Feed } \\
\text { speed }(\mathrm{mm} / \mathrm{min})\end{array}$ & $\begin{array}{c}1 \text { order vibration } \\
\text { frequency }(\mathrm{Hz})\end{array}$ & $\begin{array}{c}2 \text { order vibration } \\
\text { frequency }(\mathrm{Hz})\end{array}$ & $\begin{array}{l}3 \text { order vibration } \\
\text { frequency }(\mathrm{Hz})\end{array}$ & $\begin{array}{l}4 \text { order vibration } \\
\text { frequency }(\mathrm{Hz})\end{array}$ & $\begin{array}{c}5 \text { order vibration } \\
\text { frequency }(\mathrm{Hz})\end{array}$ \\
\hline 60 & 164.9 & null & 370.9 & 427.2 & 475.9 \\
\hline 65 & 165.2 & 353.5 & 376.2 & 430.7 & Null \\
\hline 70 & 165.4 & 353.8 & 376.2 & 427.7 & Null \\
\hline 75 & 164.9 & 352.5 & 372.5 & 426.6 & Null \\
\hline 80 & 164.3 & Null & 373.8 & 426.7 & Null \\
\hline 85 & 164.8 & Null & 371.3 & 427.1 & Null \\
\hline 90 & 163.8 & Null & 369.2 & 423.5 & Null \\
\hline 95 & 164.5 & 350.3 & 376.3 & 425.9 & 474.8 \\
\hline 100 & 164.0 & Null & 372.9 & 425.2 & Null \\
\hline 105 & 164.4 & Null & 373.8 & 427.5 & Null \\
\hline
\end{tabular}

\section{Analysis of Vibration Displacement Variation of Workpiece in Turning}

As shown in Figure 7 and 8 respectively, for the two eddy current sensor to collect the workpiece $Y$ direction and $X$ direction of the vibration displacement change pattern. By analyzing Fig 7 and Fig 8 , it can be found that the amplitude of vibration in the $\mathrm{Y}$ direction is larger than that in the $\mathrm{X}$ direction. Feeding speed of $95 \mathrm{~mm} / \mathrm{min}$ will lead to a significant increase in the amplitude of the workpiece vibration. Feed speed affects the vibration of the workpiece at different locations.

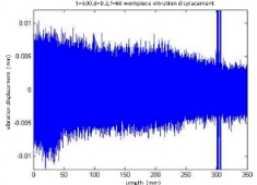

(a) $\mathrm{f}=60 \mathrm{~mm} / \mathrm{min}$

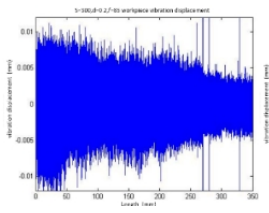

(f) $\mathbf{f}=\mathbf{8 5} \mathrm{mm} / \mathbf{m i n}$

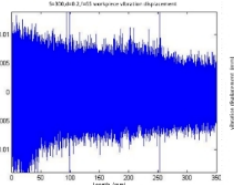

(b) $f=65 \mathrm{~mm} / \mathrm{min}$

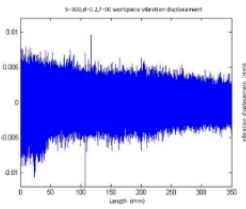

(g) $\mathbf{f}=90 \mathrm{~mm} / \mathrm{min}$

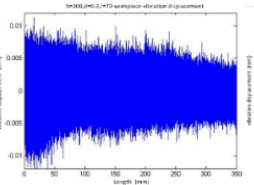

(c) $\mathbf{f}=70 \mathrm{~mm} / \mathrm{min}$

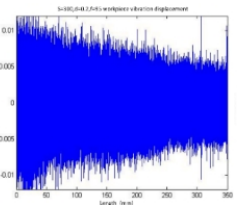

(h) $\mathbf{f}=95 \mathrm{~mm} / \mathrm{min}$

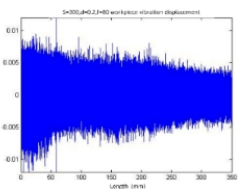

(d) $f=75 \mathrm{~mm} / \mathrm{min}$ (e) $\mathrm{f}=80 \mathrm{~mm} / \mathrm{min}$
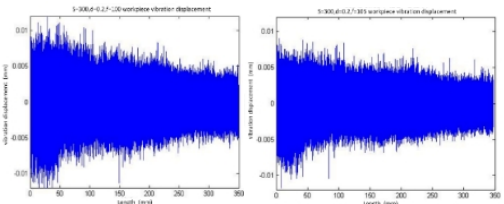

(i) $f=100 \mathrm{~mm} / \mathrm{min}$ (j) $f=105 \mathrm{~mm} / \mathrm{min}$

Fig 7 Variation of vibration displacement in the $Y$ direction of workpiece in different feed velocity

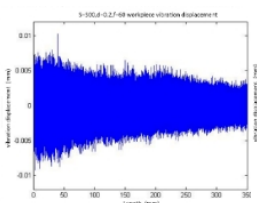

(a) $\mathrm{f}=60 \mathrm{~mm} / \mathrm{min}$

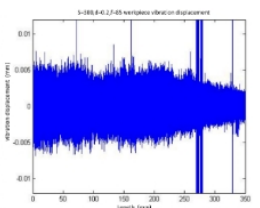

(f) $f=85 \mathrm{~mm} / \mathrm{min}$

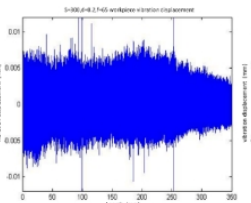

(b) $f=65 \mathrm{~mm} / \mathrm{min}$

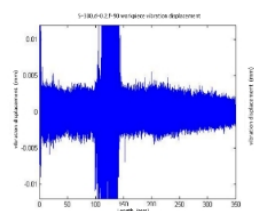

(g) $\mathrm{f}=90 \mathrm{~mm} / \mathrm{min}$

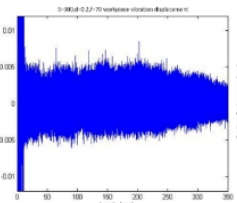

(c) $\mathrm{f}=70 \mathrm{~mm} / \mathrm{min}$

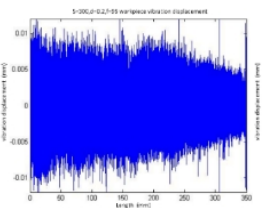

(h) $\mathbf{f}=95 \mathrm{~mm} / \mathrm{min}$
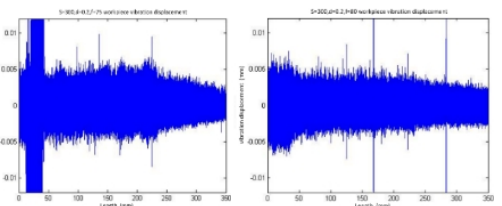

(d) $f=75 \mathrm{~mm} / \mathrm{min}$

(e) $f=80 \mathrm{~mm} / \mathrm{min}$

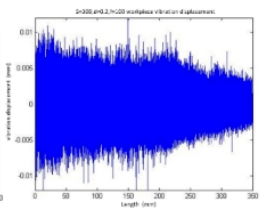

(i) $\mathrm{f}=100 \mathrm{~mm} / \mathrm{min}$

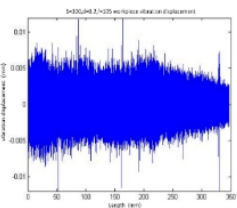

(j) $f=105 \mathrm{~mm} / \mathrm{min}$

Fig 7 Variation of vibration displacement in the $\mathrm{Y}$ direction of workpiece in different feed velocity 


\section{Analysis of Surface Vibration of Turning Workpiece}

The workpiece is machined at different feed speeds, and surface is photographed as shown in Figure 9. From these pictures can be seen, with the feed rate increases, the workpiece surface vibration marks have an increasing trend. When the speed is $95 \mathrm{~mm} / \mathrm{min}$, the vibration mark is the most, indicating the vibration of the workpiece is larger and the flutter phenomenon occurs.

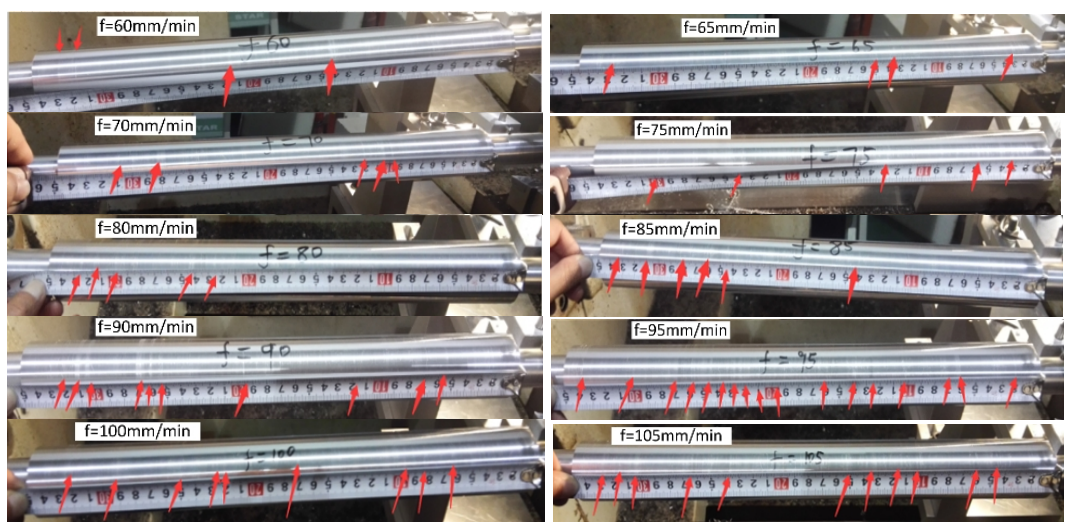

Fig 8 Surface condition of the workpiece after different feeding speed

\section{Analysis of Surface Roughness of Turning Workpiece}

The surface roughness of the slender workpiece is measured with a roughness meter of the model Mitutoyo SJ 210. The roughness of the $100 \mathrm{~mm}$ of the right end of the workpiece is shown in Figure 10. It can be seen from Figure 10 that the roughness tends to increase as the feed rate increases. When the feed rate is $95 \mathrm{~mm} / \mathrm{min}$, the surface roughness value reaches the peak value, indicating that the vibration of the workpiece is large and the flutter phenomenon occurs.

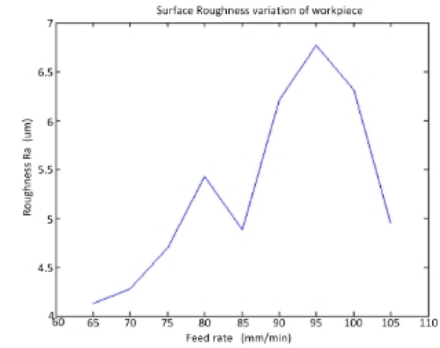

Fig 9 Roughness Ra variation diagram

\section{Effect of Feeding Speed on Cutter Vibration}

Taking the tool as the research object, the influence of the feed rate on the tool mode parameters, the moving load and the self - power spectral density is discussed. During the turning process, the moving load acting on the workpiece in three directions has a very important effect on the turning vibration. The vibration frequency of the tool, the amount of load change and the self-power spectral density are affected.

\section{Static and Dynamic Mode Analysis of the Cutter}

The cutter is clamped together with the Kistler 9257A dynamometer on the tool holder to measure the moving load of the tool in the three directions of the cutter. The tool modal parameters under the static knock are shown in Table 3. The design of the model analysis experiment under the dynamic state (ie, the turning state) is similar to that of the tool's static percussion experimental arrangement. In contrast to Table 3 and Table 4, it can be found that some modal parameters under different feed rate in dynamic turning are similar to static knocking. Feed rate has different influence on the modal parameters of the tool in three directions, $\mathrm{Y}>\mathrm{X}>\mathrm{Z}, \mathrm{Y}$ is the main vibration direction. In the $\mathrm{X}$ and $\mathrm{Y}$ 
directions, feed rate has little effect on the low-order vibrational frequency, but a great influence on the high-order vibrational frequency.

Table $3 \mathrm{Z}$, Y-direction static percussion mode parameters

\begin{tabular}{ccccc}
\hline modal order & Z natural frequency $(\mathrm{Hz})$ & $\mathrm{Z}$ damping ratio & Y natural frequency $(\mathrm{Hz})$ & $\mathrm{Y}$ damping ratio \\
\hline 1 & 1331.7 & 1.8 & 1338.5 & 2.0 \\
2 & 1673.0 & 2.7 & 1666.5 & 3.3 \\
3 & 1906.5 & 1.2 & null & null \\
4 & 2443.4 & 2.4 & 2382.6 & 1.8 \\
\hline
\end{tabular}

Table 4 vibration frequency of $X, Y$ and $Z$ in different feed speed

\begin{tabular}{cccc}
\hline $\begin{array}{c}\text { Feed } \\
\text { speed }(\mathrm{mm} / \mathrm{min})\end{array}$ & Z 1-4 order vibration frequency(Hz) & X 1-4order vibration frequency $(\mathrm{Hz})$ & Y 1-4order vibration frequency $(\mathrm{Hz})$ \\
\hline 60 & $1551.4 、 2436.5 、 2767.9 、 2935.4$ & $1362.9 、 2213.0 、 2558.0 、$ & $1392.0 、 2420.7 、 2880.1 、$ \\
65 & $1548.8 、 2413.3 、 2765.7 、 2927.9$ & $1370.9 、 2221.2 、 2577.0 、$ & $1419.6 、 2042.0 、 2402.9 、$ \\
70 & $1547.6 、 2417.3 、 2771.6 、 2924.6$ & $1371.1 、 2215.8 、$ null、 & $1457.0 、 2411.3 、$ null、 \\
75 & $1548.4 、 2409.2 、 2753.3 、 2948.3$ & $1375.8 、 2225.0 、 2577.7 、$ & $1375.1 、 2406.1 、 2886.9 、$ \\
80 & $1545.9 、 2428.0 、$ null、2924.9 & $1368.2 、 2225.0 、 2547.6 、$ & $1383.2 、 2408.5 、 2874.2 、$ \\
85 & $1547.3 、 2421.8 、 2741.5 、 2920.3$ & $1377.7 、 2228.8 、 2543.6 、$ & $1468.2 、 2394.9 、 2874.5 、$ \\
90 & $1545.1 、 2422.0 、 2702.8 、 2931.5$ & $1378.2 、 2232.7 、 2562.3 、$ & $1438.3 、 2382.2 、$ null、 \\
95 & $1547.3 、 2397.9 、 2730.0 、 2921.2$ & $1372.6 、 2240.7 、$ null、 & null、2378.2、2879.4、 \\
100 & $1547.3 、 2441.2 、 2714.9 、 2922.4$ & $1381.4 、 2250.8 、$ null、 & $1459.9 、 2364.4 、 2867.5 、$ \\
105 & $1549.9 、 2407.4 、 2708.0 、 2938.9$ & $1379.1 、 2240.9 、$ null、null & $1420.6 、 2382.2 、$ null、 \\
\hline
\end{tabular}

\section{Analysis of the Change of Moving Load at Different Feeding Speeds}

The cutting length of the bar is $350 \mathrm{~mm}$. The measured signal is converted to the LMS data acquisition system by Kistler 5070 signal amplifier, and then analyzed by LMS software. The data are processed by Matlab and the graphs of the moving load changes in $\mathrm{X}, \mathrm{Y}$ and $\mathrm{Z}$ directions shown in Figure 11 are obtained. According to Fig 11, we can see that the average value and the maximum value of the load in each direction increases with the increase of the feed velocity $\mathrm{f}$, but when $\mathrm{f}=$ $95 \mathrm{~mm} / \mathrm{min}$, the load changes in the three directions become very large, indirectly reflecting the vibration at this speed larger. The maximum load change is in the Y direction, and the smallest in the $\mathrm{Z}$ direction.
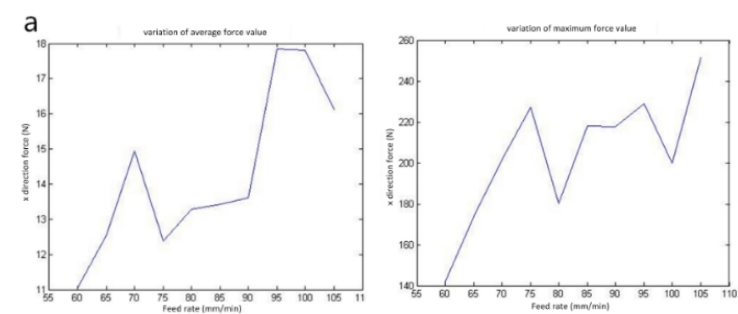

(a) Moving load changes of $\mathbf{x}$ direction

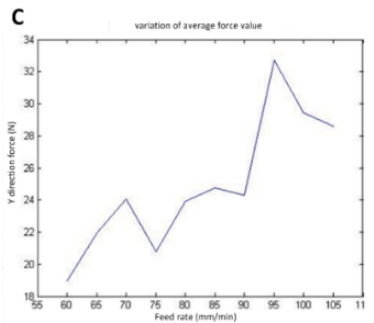

(c) Moving load changes of $\mathrm{Y}$ direction
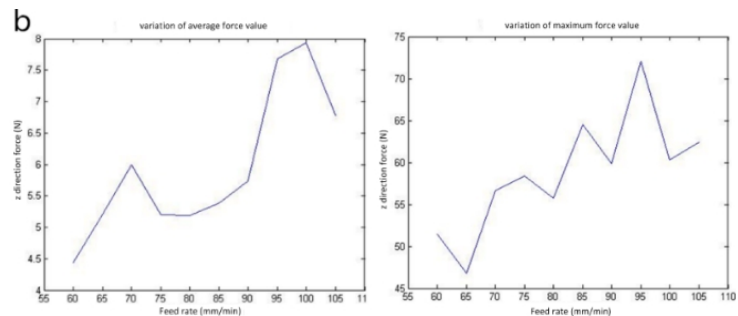

(b) Moving load changes of $\mathrm{z}$ direction

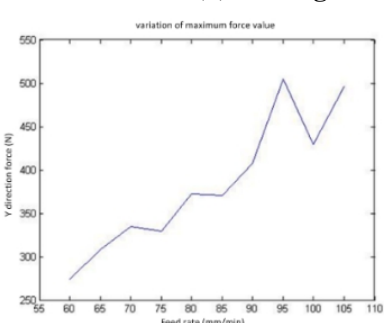

$$
\text { on }
$$

Fig 10 Variation of moving load in three directions of different feed speed 


\section{Analysis in the Change of Cutter's Power Spectrum Density}

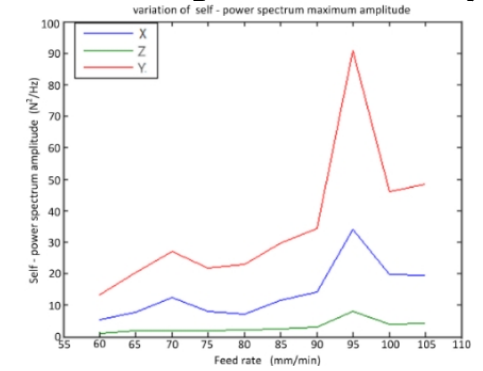

Fig 11 Variation of tool's self-power spectral density

The experimental data is analyzed by LMS software, while the frequency analysis bandwidth is set to $0-4100 \mathrm{~Hz}$ The variations of maximum self-power spectrum and the corresponding vibration frequency at different speeds are analyzed by Matlab, as shown in Figure 12. It can be seen from the figure that with the increase of feed rate, the vibration energy tends to increase as a whole, but when $\mathrm{f}$ $=95 \mathrm{~mm} / \mathrm{min}$, the vibration energy of the tool becomes very large, which reflects the vibration is very larger at this speed. The amplitude of the self-power spectral density is $\mathrm{Y}>\mathrm{X}>\mathrm{Z}$, indicating that the $\mathrm{Y}$ direction is the main vibration direction.

\section{Conclusion}

Based on the moving load theory, the vibration influence of the workpiece and cutter in the turning process is analyzed from the view of the feed rate change, and the effect of feed rate on turning stability is studied through the concrete experiment. However, the machine tool cutting system is a very complex structure that works under variable conditions. The effect of the structural parameters (system natural frequency, tool nose radius, etc.) and cutting process factors (spindle speed, tool wear, etc.) on cutting vibration is very complex. It is not enough to control the feed rate to reduce the cutting vibration. Looking forward to the future, slender shaft cutting vibration under action of moving load, also needs to carry out further theoretical research and practice test.

\section{Acknowledgments}

This work is supported by Natural Science Foundation of China (No. 51375193 and No. 51505084).

\section{References}

[1] Ouyang H. Moving-load dynamic problems: A tutorial (with a brief overview)[J]. Mechanical Systems and Signal Processing, 2011, 25(6): 2039-2060.

[2]Taylor F W. On the art of cutting metals[J]. 1907.

[3] Tobias S A, Fishwick W. Theory of regenerative machine tool chatter[J]. The engineer, 1958, 205(7): 199-203.

[4] Tobias S A, Fishwick W. The vibrations of radial-drilling machines under test and working conditions[J]. Proceedings of the Institution of Mechanical Engineers, 1956, 170(1): 232-264.

[5] Tobias S A, Fishwick W. The chatter of lathe tools under orthogonal cutting conditions[J]. Trans. ASME, 1958, 80(2): 1079-1088.

[6] Tlusty J, Polacek M. The stability of machine tools against self-excited vibrations in machining[J]. International research in production engineering, 1963, 1(1): 465-474.

[7] Merritt H E. Theory of Self-Excited Machine-Tool Chatter: Contribution to Machine-Tool Chatter Research-[J]. Journal of engineering for industry, 1965, 87(4): 447-454.

[8] Vela-Martínez L, Jáuregui-Correa J C, Rubio-Cerda E, et al. Analysis of compliance between the cutting tool and the workpiece on the stability of a turning process[J]. International Journal of Machine Tools and Manufacture, 2008, 48(9): 1054-1062. 
[9] Sekar M, Srinivas J, Kotaiah K R, et al. Stability analysis of turning process with tailstock-supported workpiece[J]. The International Journal of Advanced Manufacturing Technology, 2009, 43(9-10): 862-871.

[10] Zhao HT, Yang JG, Tong HC. The vibration of thin shaft turning and its compensation control [J]. Journal of Shanghai Jiaotong University, 2005, 39(1): 117-120.

[11] Zhang MQ, Xing EH. A method to slow the vibration of thin shaft turning [J]. Journal of jiamusi university: natural science edition, 2007, 25(2): 169-171.

[12] Cui BD. Study on optimization and size error monitoring system for thin shaft turning parameters [D]. HIT(Harbin Institute of Technology), 2008.

[13] Ouyang H, Wang M. A dynamic model for a rotating beam subjected to axially moving forces[J]. Journal of Sound and Vibration, 2007, 308(3): 674-682.

[14] Ouyang H, Wang M. Dynamics of a rotating shaft subject to a three-directional moving load[J]. Journal of vibration and acoustics, 2007, 129(3): 386-389.

[15]Zhang W. Several discussions of the Timoshenko axis model [J]. Chinese Quarterly of Mechanics, 1987, 3: 006.

[16] $\mathrm{Lu} \mathrm{ZX}$. The bending-torsional coupling vibration study of the rotating shaft [J]. Turbine Technology, 1994, 36(5): 266-268

[17] Katz R, Lee C W, Ulsoy A G, et al. Dynamic stability and response of a beam subject to a deflection dependent moving load[J]. Journal of vibration, acoustics, stress, and reliability in design, 1987, 109(4): 361-365.

[18] Lee C W, Katz R, Ulsoy A G, et al. Modal analysis of a distributed parameter rotating shaft[J]. Journal of Sound and Vibration, 1988, 122(1): 119-130.

[19] Katz R, Lee C W, Ulsoy A G, et al. The dynamic response of a rotating shaft subject to a moving load[J]. Journal of Sound and Vibration, 1988, 122(1): 131-148. 